\title{
Meiofauna as a model to test paradigms of ecological metacommunity theory
}

\author{
Birgit Gansfort $\mathbb{D} \cdot$ Diego Fontaneto $\cdot$ Marie Zhai
}

Received: 7 June 2019/Revised: 21 December 2019/Accepted: 22 January 2020/Published online: 15 February 2020

(C) The Author(s) 2020

\begin{abstract}
The metacommunity concept incorporates spatial dynamics into community ecology, shedding light on how local and regional processes interact in structuring ecological communities, and to which measure they are deterministic or stochastic. We reviewed metacommunity studies on freshwater meiobenthos published since 2004, when the main principles of metacommunity theory were conceptualized. The studies (together 19) were observational, focused mainly on ostracods, and rarely on rotifers and nematodes. In accordance with general expectations, the prevalent structuring force was species sorting.
\end{abstract}

Guest editors: Nabil Majdi, Jenny M. Schmid-Araya \& Walter Traunspurger / Patterns and Processes of Meiofauna in Freshwater Ecosystems

Electronic supplementary material The online version of this article (https://doi.org/10.1007/s10750-020-04185-2) contains supplementary material, which is available to authorized users.

B. Gansfort $(\bowtie)$

Department Animal Ecology, Bielefeld University, Konsequenz 45, 33615 Bielefeld, Germany

e-mail: birgit.gansfort@uni-bielefeld.de

D. Fontaneto

Water Research Institute, National Research Council of Italy, Verbania Pallanza 28922, Italy

M. Zhai

Department Botany and Zoology, Masaryk University, Kotlářská 2, Brno 61137, Czech Republic
Ostracods showed more dispersal limitations than nematodes and rotifers, and there was very little support for dispersal surplus. We discussed the role of body size, dispersal mode, and attachment to sediment for the meiofauna dispersal. Effects of metacommunity context (habitat connectivity, spatial extent, and environmental heterogeneity), study design (e.g., sample size), and statistical approach could not be sufficiently disentangled due to the low number of studies. Local stochasticity, consistent with neutral theory and patch dynamics, was indicated for taxa with weak specialization and metacommunities in small habitats. Our understanding of meiofaunal metacommunities is only fragmentary and it would highly benefit from direct comparisons of taxa with different species traits and between different spatial scales, and studies incorporating temporal dynamics and hypothesis-driven experiments.

Keywords Meiobenthos - Species sorting - Mass effects $\cdot$ Neutral theory $\cdot$ Patch dynamics $\cdot$ Dispersal limitation 


\section{Introduction}

Metacommunity theory

A central goal in ecology is to distinguish between the different factors that influence species occurrence and abundance and determine their roles in the assembly of communities. Expanding such studies beyond a local spatial scale to a regional view can shed light on how the regional species pool affects local community dynamics (Leibold et al., 2004; Holyoak et al., 2005). The metacommunity concept incorporates regional dynamics into community ecology research and over the last few decades has become a powerful tool for determining (i) the relative importance of spatial (i.e., regional, dispersal-related) and environmental (i.e., local, niche-based) processes in structuring communities (Cottenie, 2005; Logue et al., 2011), and (ii) the extent to which local and regional processes are deterministic or stochastic (Vellend et al., 2014).

The term 'metacommunity' formally defines a set of local communities potentially linked by dispersal (Wilson, 1992). The interest in metacommunity theory grew rapidly after 2004, in response to two publications (Leibold et al., 2004; Holyoak et al., 2005) that conceptually divided the different approaches in metacommunity theory into (i) patch dynamics, (ii) species sorting, (iii) mass effects, and (iv) a neutral perspective. These four paradigms of metacommunity structure (Leibold \& Chase, 2018) differ in their assumptions regarding both the degree of stochasticity in local and regional processes and the dispersal rate among local communities (Table 1). Local processes refer (i) to resource utilization by species and interspecific interactions, i.e., the competitive abilities of species, and (ii) to demographic processes, such as the relationship between birth and death rates and changes in abundance. On a regional scale, the roles of environmental heterogeneity and dispersal become important. Dispersal can influence metacommunity structure in three distinct ways according to its rate. If dispersal is limited, species cannot reach every site where they could otherwise persist. In the absence of dispersal barriers, the amount of dispersal will be sufficient for a species to track environmental gradients and to establish populations at any suitable site. In the case of surplus dispersal, a species may persist even in suboptimal habitats due to its constant immigration from neighboring suitable sites (i.e., source-sink dynamics).

The paradigm with the simplest assumptions is neutral theory (Hubbell, 2001), in which both demography and dispersal are completely stochastic, and species are treated as identical in their responses to environment. By contrast, the species-sorting paradigm highlights the individual responses of species to environmental heterogeneity due to differences in both resource utilization and interspecific interactions, while dispersal is not limited, resulting in purely deterministic effects. This paradigm is consistent with the traditional niche-based approach in ecology (i.e., coexistence theories, e.g., Gause, 1936; Levin, 1970). A considerable effort has been made to reconcile these two opposing paradigms within the metacommunity concept (Gravel et al., 2006).

Patch dynamics and mass effects, although presented as qualitatively distinct paradigms by Leibold et al. (2004), can be seen as special cases of species sorting (Winegardner et al., 2012; Heino et al., 2015a). In patch dynamics, the interacting species differ including their colonization and/or competitive abilities, which potentially produces a spatial pattern even in homogeneous environment. For mass effects it is assumed that species use different niches but, contrary to species sorting, some species reach dispersal surplus, which contributes to a spatial structure along with responses of other species to heterogeneous environment.

The four metacommunity paradigms represent simple and theoretically consistent models, but they are based on relatively little experimental and observational data (Logue et al., 2011). Natural metacommunities are probably structured by a combination of several interacting deterministic and/or stochastic processes that are consistent with at least two of the paradigms (Cottenie, 2005; Gravel et al., 2006; Leibold \& Chase, 2018). Good empirical evidence has been assembled especially for both niche differentiation of locally coexisting species and for species responses to environmental heterogeneity, in accordance with species sorting (Leibold \& Chase, 2018). Evidence of dispersal limitations has been obtained for species in several ecosystems (e.g., Tilman, 1997). Demographic stochasticity, especially during the initial stages of colonization, was shown to lead to local communities of different composition via ecological drift, regardless of whether the species were of 
Table 1 The four metacommunity paradigms describing processes and effects relevant at local and regional scales (after Leibold \& Chase, 2018). According to Winegardner et al. (2012) patch dynamics and mass effects are special cases of species sorting, which is indicated by dashed line. The different shades of gray indicate the degree of stochasticity: stochastic (dark), partly stochastic (medium), and deterministic (light). For the processes shown in white boxes this distinction is irrelevant

\begin{tabular}{|c|c|c|c|c|}
\hline \multirow[b]{2}{*}{ Paradigm } & \multicolumn{2}{|c|}{ Local scale } & \multicolumn{2}{|c|}{ Regional scale } \\
\hline & $\begin{array}{l}\text { Resource utilization } \\
\text { and response }\end{array}$ & Demographic processes & $\begin{array}{l}\text { Environmental } \\
\text { heterogeneity }\end{array}$ & Dispersal \\
\hline Neutral theory & $\begin{array}{l}\text { All species are } \\
\text { identical in resource } \\
\text { use and in their } \\
\text { interactions }\end{array}$ & $\begin{array}{l}\text { Birth-death rates are } \\
\text { stochastic }\end{array}$ & Not relevant & Limitation \\
\hline Species sorting & $\begin{array}{l}\text { Species differ in their } \\
\text { resource use and } \\
\text { interactions }\end{array}$ & $\begin{array}{l}\text { Birth-death rates are } \\
\text { deterministic, } \\
\text { depending on } \\
\text { environmental } \\
\text { conditions }\end{array}$ & $\begin{array}{l}\text { Heterogeneous } \\
\text { environment }\end{array}$ & Sufficient \\
\hline Patch dynamic & $\begin{array}{l}\text { Species differ in their } \\
\text { resource use and } \\
\text { interactions }\end{array}$ & $\begin{array}{l}\text { Population extinctions } \\
\text { can be stochastic }\end{array}$ & $\begin{array}{l}\text { Homogeneous } \\
\text { environment, but } \\
\text { spatial } \\
\text { heterogeneity in } \\
\text { response to the } \\
\text { environment is } \\
\text { allowed }\end{array}$ & $\begin{array}{l}\text { Limitation, but } \\
\text { species differ } \\
\text { in their } \\
\text { colonization } \\
\text { abilities }\end{array}$ \\
\hline Mass effect & $\begin{array}{l}\text { Species differ in their } \\
\text { resource use and } \\
\text { interactions }\end{array}$ & $\begin{array}{l}\text { Birth-death rates are } \\
\text { deterministic, } \\
\text { depending on } \\
\text { environmental } \\
\text { conditions }\end{array}$ & $\begin{array}{l}\text { Heterogeneous } \\
\text { environment }\end{array}$ & Surplus \\
\hline
\end{tabular}

different or similar niches (e.g., Chase, 2007; Siepielski \& McPeek, 2010). Priority effects may occur when the first colonizers change the probability of immigration by other species, consistently with the patch dynamic model (e.g., Shurin et al., 2004).

Metacommunity analyses

Both observational and experimental approaches have been used to examine different aspects of metacommunities (Logue et al., 2011; Leibold \& Chase, 2018). Many of those studies focused on patterns in the relative abundances, distributions, and co-occurrences of species in the context of metacommunity theory, including analyses of diversity, species-abundance distributions, and species-area relationships. A relatively widely used approach is the analysis of species distribution patterns based on incidence matrices; that is, testing checkerboards, turnover, and nestedness against differently set null models. These attempts were assessed and integrated by Leibold and Mikkelson (2002) and further improved by Presley et al. (2010) to yield the concept of elements of metacommunity structure (EMS).

A statistical approach allowing to relate metacommunity patterns either to environmental differences or dispersal, or both is provided by direct gradient analyses (canonical correspondence analysis, CCA; redundancy analysis, RDA) (Borcard et al., 1992; Cottenie, 2005), combined by partitioning the variance in species composition into the components attributable to pure effect of environmental variables (EIS), pure effect of spatial variables (SIE), the shared

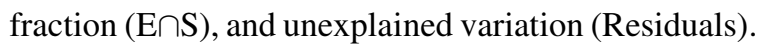
The spatial variables in those analyses are generated based on the geographical distances among sites, using either principle coordinates on neighbor matrices (PCNM), Moran eigenvector maps (MEMs), or 
asymmetric eigenvector maps (AEMs) (Legendre \& Legendre, 2012). Variation partitioning has gained wide acceptance among ecologists as a suitable method to assess the relative importance of environmentally induced and dispersal-based processes (Soininen, 2014). Nonetheless, despite the utility of those pattern-based approaches (both EMS and variation partitioning), they do not allow to unequivocally deduce a process from an observed pattern, because the same patterns may arise due to different processes (Leibold \& Chase, 2018).

The impact of regional and local processes on species within a metacommunity framework has been addressed in several experimental studies. These have mostly been conducted in aquatic environments and have examined the relationship of species diversity and biomass or abundances to different dispersal modes or intensities (reviewed by Logue et al., 2011).

\section{Aquatic metacommunities}

Metacommunity research of aquatic environments has rapidly progressed over the last decade, especially in freshwater systems (Heino et al., 2015a). Several characteristics of freshwater habitats have highly important consequences especially for the dispersal of organisms. First, it is the degree of habitat connectedness versus isolation (Olden et al., 2001), and spatial organization and flow directionality in stream networks (Brown \& Swan, 2010; Landeiro et al., 2011; Milesi et al., 2014). Dispersal in aquatic systems can be realized overland and via the watercourse, both down- and upstream (Beisner et al., 2006; Grönroos et al., 2013; Tonkin et al., 2018), depending on a specific topography of the region (Juračka et al., 2016). Further, it is the habitat size and stability of aquatic habitats, which affect colonization-extinction processes, and environmental and temporal heterogeneity (Wellborn et al., 1996; Chase, 2007; Vanschoenwinkel et al., 2010). Accordingly, the metacommunity structure differs among streams, lakes, ponds, and temporary ponds (Heino et al., 2015a). However, an effect of spatial extent occurs consistently across all types of aquatic habitats. In streams (Mykrä et al., 2007), lakes (Soininen et al., 2011), and temporary ponds (Declerck et al., 2011), the relative importance of spatial structure increases on larger spatial scales (i.e., across different drainage basins, distant wetlands, or valleys).
Dispersal abilities of taxa

The key species traits determining dispersal abilities are body size and dispersal mode (De Bie et al., 2012). In freshwater environments, large organisms are generally less effective dispersers than small ones (Beisner et al., 2006; Shurin et al., 2009; Padial et al., 2014). Small organisms cannot move actively between suitable patches and rely on some form of passive dispersal by mobile elements, such as wind, water currents, and animal agents (Bohonak \& Jenkins, 2003; Rundle et al., 2007; Fontaneto, 2019). The passive dispersal of microscopic organisms may be highly effective, leading to spatially unlimited distributions either on global (Fenchel \& Finlay, 2004; Fontaneto, 2019) or regional (Beisner et al., 2006) scales. The threshold between large and small body size, determining the dispersal success, is still a matter of debate (Fenchel \& Finlay, 2004; Shurin et al., 2009).

In this review, we focus on freshwater meiofauna (here used synonymously to meiobenthos), a group of benthic invertebrates with size range between macroand microfauna. Specifically, they are defined as fauna able of passing through a 500-1000 $\mu \mathrm{m}$ sieve but being retained on a $42-63 \mu \mathrm{m}$ sieve (the size limits differ according to authors, e.g., Fenchel, 1978; Higgins \& Thiel, 1988; Giere, 2009). Freshwater meiofauna includes a number of taxa with various phylogenetic origin (e.g., tardigrades, gastrotrichs, rotifers, nematodes, water mites, harpacticoids, and ostracods). Theoretically, meiofauna has unlimited dispersal abilities due to its small size and frequent adaptations against desiccation (Martens et al. 2008; García-Roger et al., 2019; Kaczmarek et al., 2019). There is a solid evidence for the frequent occurrence of some meiofauna (bdelloid rotifers, tardigrades, and nematodes) in wind-dispersed samples (Jenkins \& Underwood, 1998; Wilson \& Sherman, 2013; Ptatscheck et al. 2018), suggesting high dispersal rates. However, there are probably significant differences in the rates and distances of dispersal among individual meiofaunal taxa (Rundle et al., 2007; Vanschoenwinkel et al., 2009; Fontaneto, 2019).

Generally, realized dispersal is strongly context and scale-dependent (Havel \& Shurin, 2004; Robeson et al., 2011), and very difficult to assess (Jacobson \& Peres-Neto, 2010), unless colonization of newly created habitats is observed (Robertson \& Milner, 
2006; Juračka et al., 2016). In fact, actual dispersal may be limited even for species with high dispersal capacities (Jenkins \& Underwood, 1998; Bohonak \& Jenkins, 2003). The dispersal rates of individual taxa with potentially different dispersal abilities may be indirectly deduced from multiple comparisons of their spatial structure (Beisner et al., 2006; Hájek et al., 2011; Grönroos et al., 2013; Padial et al., 2014; Rádková et al., 2014; Heino et al., 2015b; Göthe et al., 2017). Unfortunately, these studies failed to account for meiofauna.

By size and passive dispersal mode meiofauna is comparable to zooplankton, suggesting similar metacommunity structures (De Bie et al., 2012). Zooplankton seem to show unlimited dispersal over some regions (Padial et al., 2014; Viana et al., 2016; Rocha et al., 2017) but significant spatial structure in others (Beisner et al. 2006). However, since meiobenthos is sediment-bound, it might have less accessibility to dispersal vectors such as drift, wind, or other animals (insects, birds), and be therefore less mobile and more spatially structured than pelagic zooplankton.

Based on body size and dispersal mode (active versus passive) of different organismal groups and in accordance with the results of the following studies (Beisner et al., 2006; De Bie et al., 2012; Grönroos et al., 2013; Padial et al., 2014; Rádková et al., 2014), the main groups of freshwater organisms can be schematically arranged according to their assumed dispersal ability, which is reciprocally linked with the probability of being influenced by spatial structure due to dispersal limitations (Fig. 1). Within this continuum, we expected meiobenthos to occupy the middle part.

\section{Aims of the review}

The aims of this review were (i) to provide an overview of the studies that have investigated freshwater meiobenthos within the metacommunity framework. We evaluated the importance assigned to (ii) niche-based, (iii) dispersal-based, and (iv) local stochastic processes in meiofaunal metacommunities in those studies, taking into account the differences of methodological approaches and metacommunity settings. The results were compared with those from studies of different groups of freshwater organisms, especially zooplankton. (v) The remaining research gaps and the challenges within meiobenthic metacommunity studies were outlined.

\section{Materials and methods}

Literature research

We performed a thorough search of the literature using a list of all potentially meiobenthic organismal groups according to Giere (2009), but excluded purely marine and terrestrial taxa, taxa that rarely occur in freshwater habitats, and taxa with size range only marginally overlapping with that of meiofauna (gastropods, oligochaetes, polychaetes, and insects). Therefore, the following keywords were used as inputs in the search engines: 'metacommunity' and at least one of the words 'meiofauna,' 'meiobenth*, 'acari*,' 'turbellaria,' 'platyhelminth*, 'rotifer*, 'nematod*, 'gastrotrich*,' 'tardigrad*,' 'crustacea*, 'cladocer*,' 'branchiopod*,' 'copepod*,' 'ostracod*,' 'malacostrac*, and 'mite*' (Giere, 2009). Only the papers published between 2004 and 2018 were considered because the term 'metacommunity' and metacommunity paradigms only became widely established in 2004.

The keywords were applied within the search engines of Google Scholar (3410 results) and Web of Science (142 results). The latter and the first 1000 results of Google Scholar were merged into one list containing 1031 potentially relevant papers. We then screened those papers, selecting (1) only the ones that assessed meiobenthic animals in freshwater habitats from the metacommunity perspective. Metacommunity was clearly addressed in 518 papers, 382 of which (at least partly) covered freshwater habitats. From that group, we chose (2) only original research papers that used a mesh size appropriate for the investigated meiobenthic groups $(\leq 250 \mu \mathrm{m}$ for ostracods, and $\leq 100 \mu \mathrm{m}$ for others). Since metacommunity patterns specific for meiofauna might be obscured in mixed metacommunities, from the 262 accordingly identified studies, we retained only those that (3) focused solely on meiobenthic animals or, if other groups were included, that separately reported the results for meiobenthic animals. Because some meiofaunal taxa occur both in/on substrates and in the water column (e.g., rotifers, copepods), we selected only those studies (4) using methods appropriate for sampling 
Assumed dispersal ability based on body size $\&$ dispersal mode

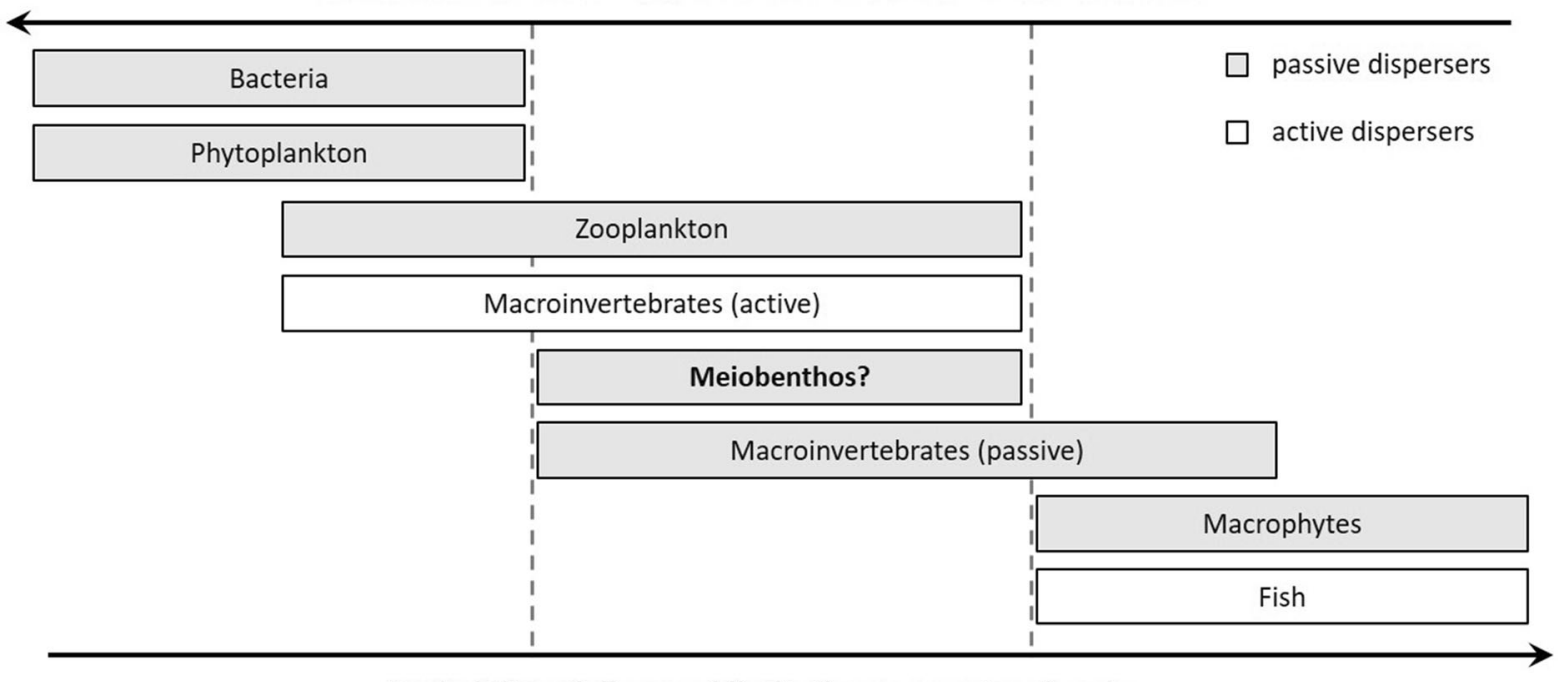

Probability of dispersal limitations on regional scale

Fig. 1 Aquatic organismal groups arranged according to their probability to be dispersal limited on a regional scale, which is negatively related to their assumed dispersal ability based on

substrate (sediment, macrophytes, moss, lichens, or periphyton) and/or that contained benthic forms in the list of the analyzed taxa.

\section{Dataset}

We obtained (a) a final selection of relevant papers on meiofauna metacommunities that became the core of this review (19 studies, Online Resource 1a). Additionally, we registered (b) a list of metacommunity studies that included meiofauna among other groups (26 studies, Online Resource 1 b), (c) metacommunity studies on zooplankton, as a reference to the state of meiofaunal research (164 studies, Online Resource 1c), and (d) papers focusing on the dispersal abilities of meiofauna and zooplankton (25 studies, Online Resource 1d).

All the relevant studies on meiobenthos (Table 2) were observational field studies and included four study types: (1) 10 studies identifying the relative roles of environmental and spatial variables in structuring species composition ("space vs. environment"); (2) one study testing models based on the assumptions of individual metacommunity paradigms ("testing paradigm”); (3) five studies evaluating species turnover (and/or nestedness) without explicitly including spatial parameters ("species distribution patterns"), and body size and dispersal mode. For macroinvertebrates, active dispersers are supposed to have better dispersal ability than passive dispersers, despite their larger size

(4) three studies analyzing diversity patterns along different spatial gradients ("diversity patterns").

From each paper, the following data were extracted: sampled habitat and substrate type, taxonomic group, geographical location, maximum distance between two sites within a metacommunity (spatial extent), sampling unit (spatial grain), sampling method, number of sites and species for each analyzed metacommunity, total number of samples, connectivity among sites, data type (presence/absence vs. abundance data), explanatory variables, and the statistical methods used in the study. For studies that used variation partitioning, we recorded the variables that were both tested and selected for environmental models (Table 2), and the pure and shared fractions of variance explained by spatial and environmental variables (Fig. 2).

The limited number of relevant studies and their large differences (see below) did not allow using statistical tests for a meta-analysis, but only qualitative comparisons. Most informative were the comparisons of studies on ostracod communities using variation partitioning, which made up the largest methodologically homogeneous group (8 studies). 


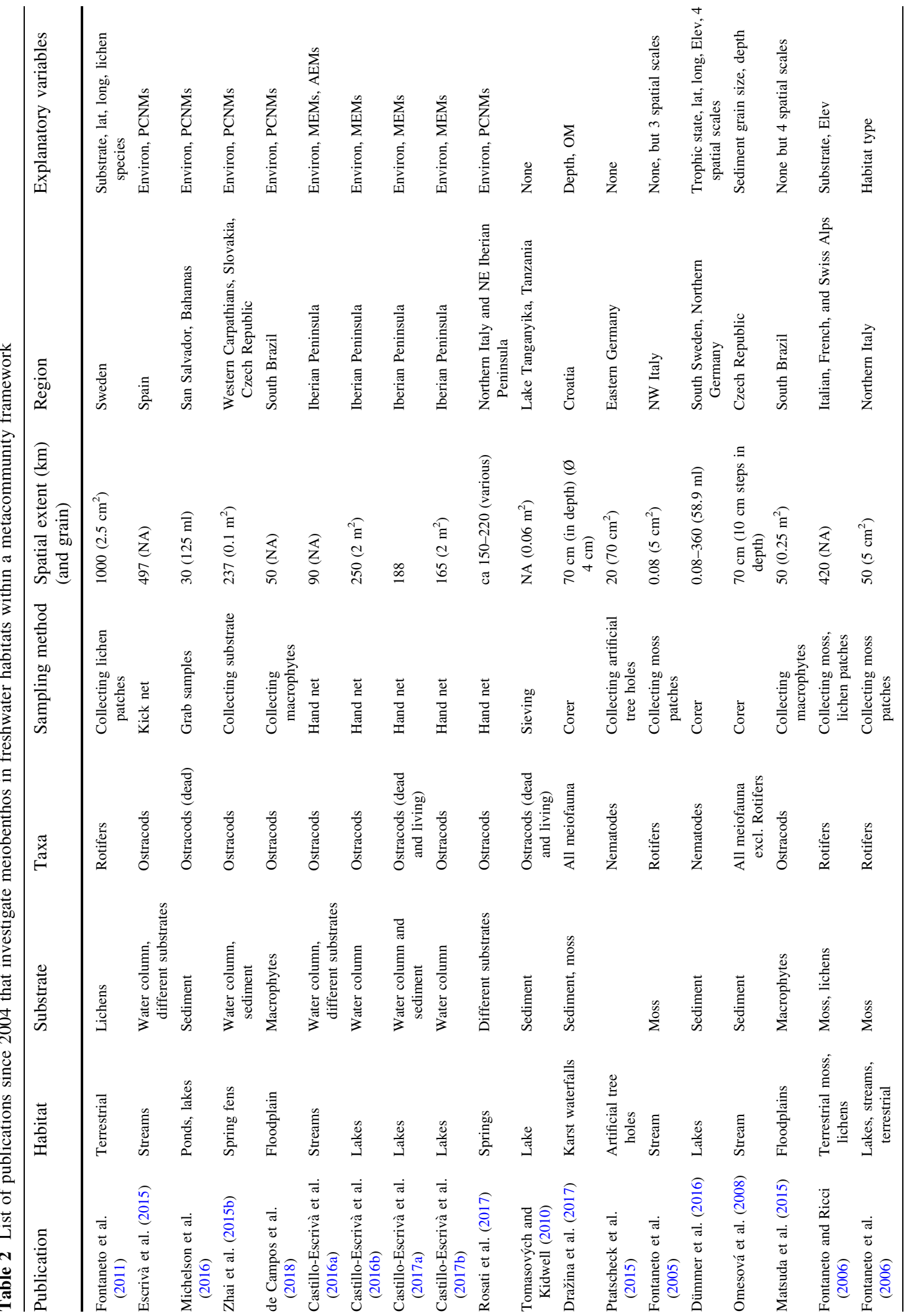




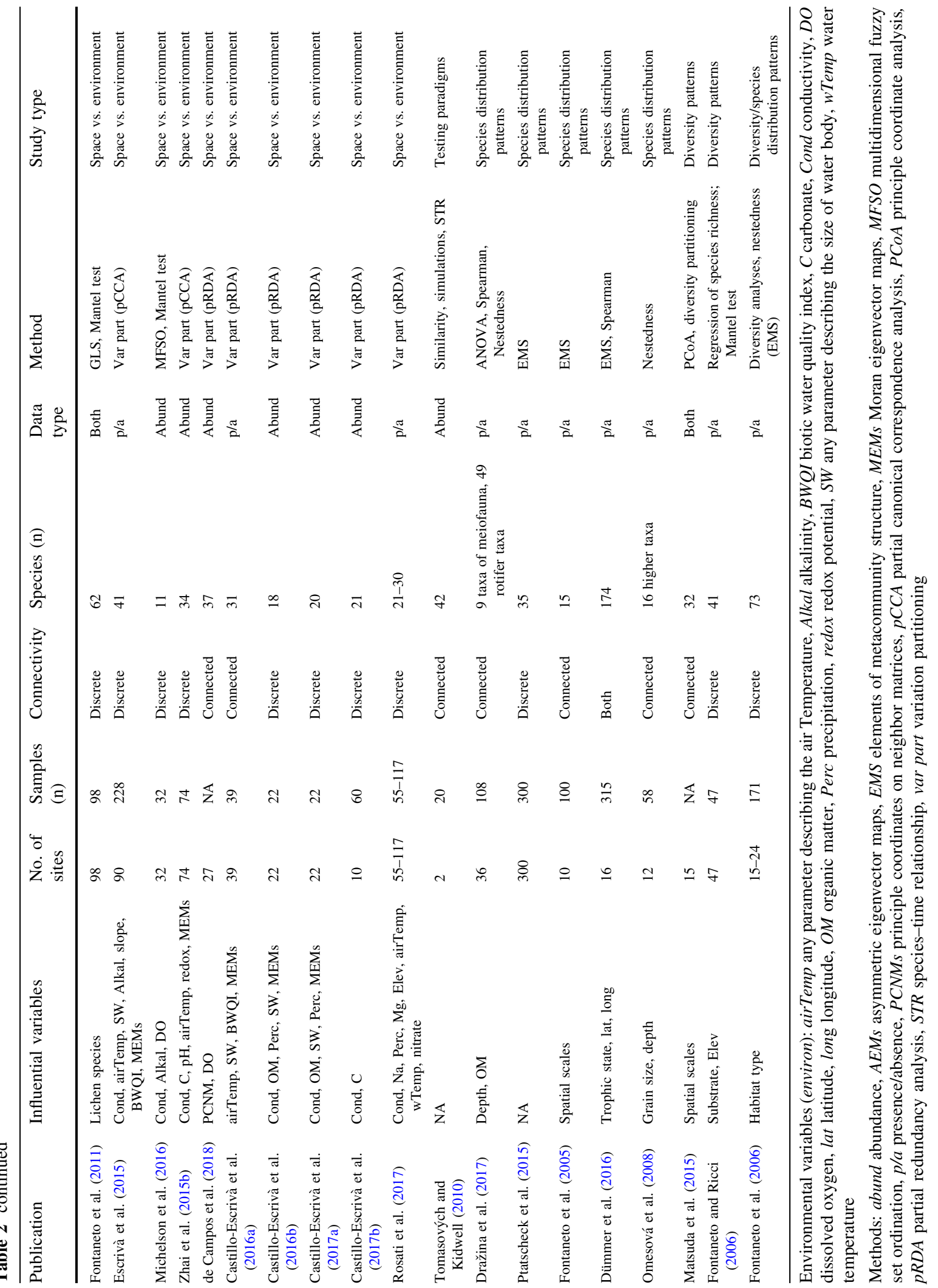


Fig. 2 The percentage of variance explained by pure fractions of environmental variables (EIS), spatial variables $(\mathrm{S} \mid \mathrm{E})$ and their shared effects $(E \cap S)$ as determined in eight ostracod metacommunity studies using variation partitioning. Only the fractions marked with ns were not significant. White bars show the spatial extent expressed as the maximum distance between sites. Habitat type and connectivity, sample size (sites $\times$ species), and the number of environmental variables included in analysis (Evar) are indicated. Two metacommunities were included from CastilloEscrivà et al. (2017a)

(I fossil ostracod community, II living ostracod community) and four from Rosati et al. (2017) (I Valencia, II Emilia Romagna, III Pyrenees, IV Alps). Dotted line delineates metacommunities from connected versus isolated sites

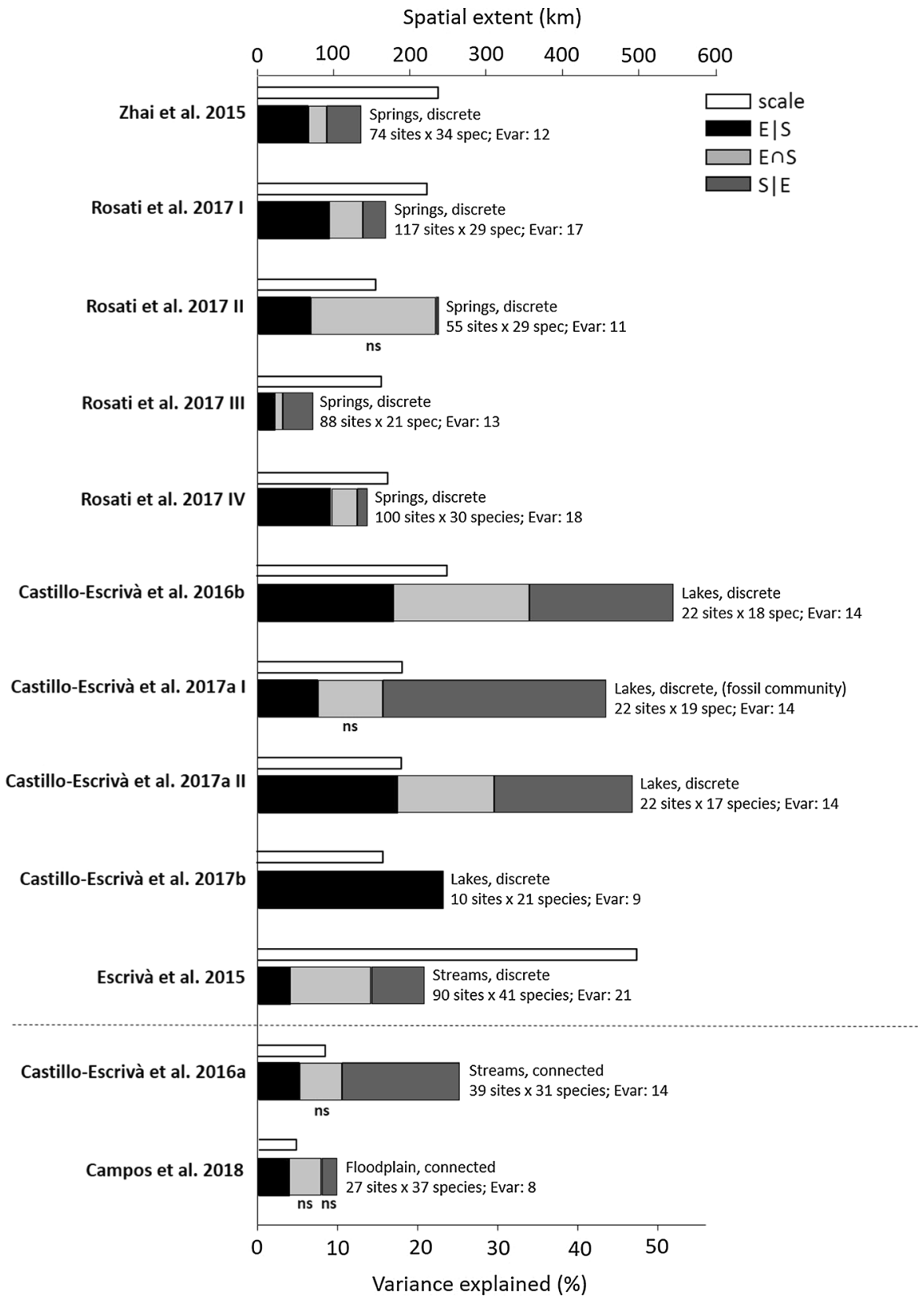

\section{Overview of identified studies}

Our overview showed that freshwater meiofauna has been so far underrepresented in metacommunity studies. All the relevant studies (19) were observational and produced by the efforts of only a few research teams in few sampling areas (Matsuda et al., 2015; as well Escrivà et al., 2015; Castillo-Escrivà et al., 2016b, 2017a, b; de Campos et al., 2018 were sampled in the same areas), thus the knowledge on metacommunity processes in meiofauna remains only fragmentary. The vast majority of the metacommunity studies focused on ostracods, and only a small number on rotifers and nematodes (Table 2), whereas other meiofaunal taxa, such as tardigrades, water mites, and harpacticoids, have been completely neglected. Further, the relevant studies largely differed in their spatial extent (ranging from a few centimeters to 


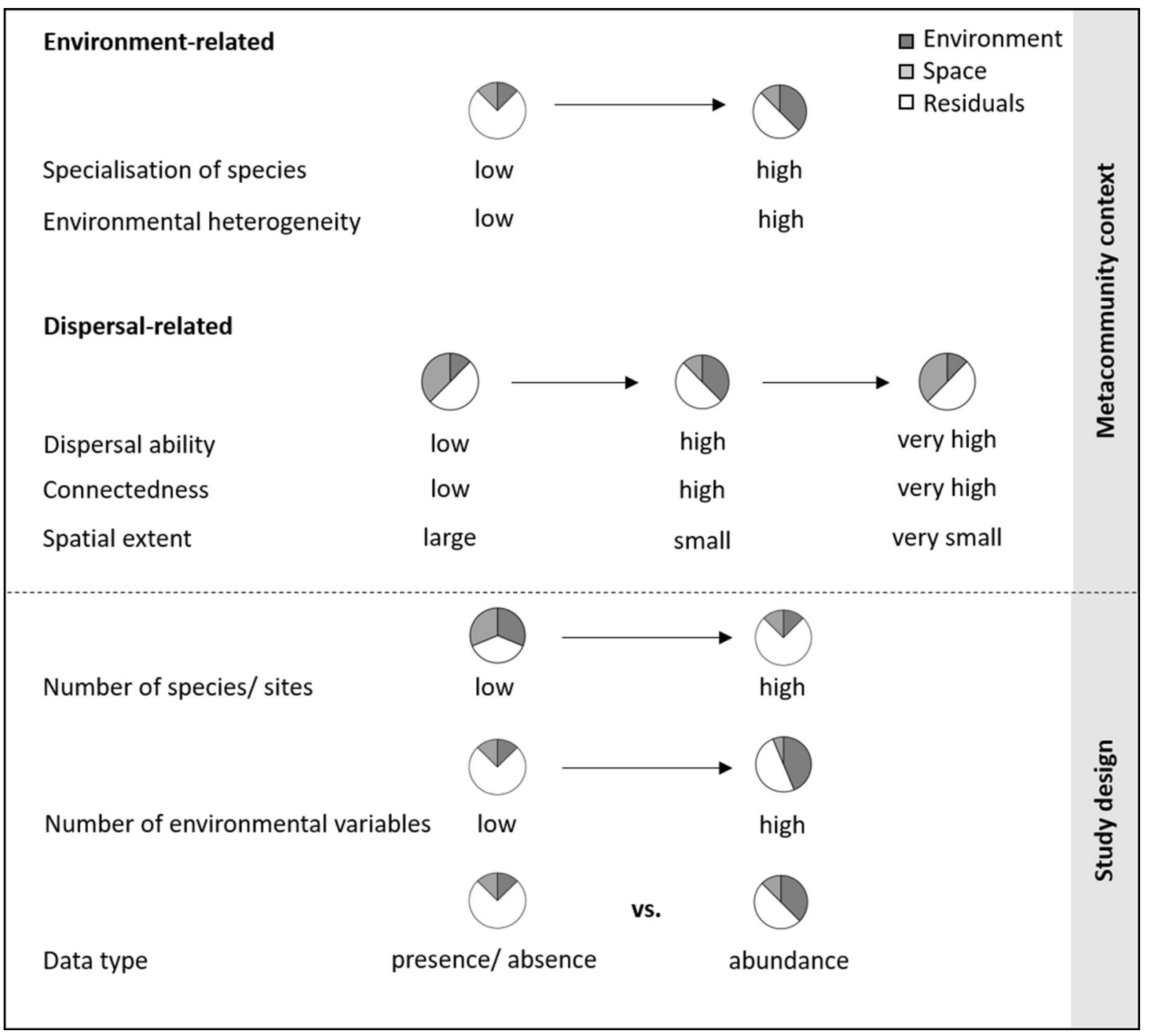

Fig. 3 Scheme of effects of study design and metacommunity context on the relative roles of environmental (dark gray) and spatial (light gray) variables for metacommunity structure and

$1000 \mathrm{~km}$ ), habitat type (lentic, lotic, limno-terrestrial habitats), and substrate (sediment versus mosses, lichens and periphyton). Moreover, used statistical methods varied even within the same study type (see Table 2). Thus, unlike comprehensive meta-analyses (e.g., Cottenie, 2005; Soininen, 2014), which allow general conclusions to be drawn despite differences among individual studies, our review may provide only limited insights into the attributes of meiofaunal metacommunities.

Nevertheless, our review confirmed mainly the importance of species sorting and its interactions with the amount of unexplained variance (white). For simplification interactions between space and environment is neglected

dispersal-based processes (predominantly dispersal limitations) at regional and larger scales. It seemed that the individual taxa of meiofauna have different dispersal abilities. To a lesser extent, there have been indications of the increased role of local stochasticity, consistent with neutral theory and patch dynamics.

Niche-based processes

All studies in our review that included environmental parameters in their analyses (15 studies, Table 2) found significant effects of environment on the 
investigated metacommunities. For example, conductivity was by far the most frequently identified environmental driver of ostracod metacommunities. This reflects both that conductivity is a gradient to which ostracods generally respond (their physiology requires to optimize shell building and the energetic expense of osmosis, Mezquita et al., 1999) and that conductivity was a large environmental gradient in these studies (Fig. 3, 'heterogeneity'). Some bdelloid rotifers were found to be significantly associated with different habitat types, i.e., lotic, lentic, and terrestrial mosses (Fontaneto et al., 2006), different substrate types (mosses vs. lichens; Fontaneto \& Ricci, 2006), and particular lichen species (Fontaneto et al., 2011). The nematode metacommunity in lakes responded to trophic state, indicative of bottom-up structuring of these communities (Dümmer et al., 2016).

The significant responses of meiofauna to environmental heterogeneity represent deterministic processes in accordance with the traditional "nichebased" concept of ecological communities and the paradigm of species sorting (Leibold \& Chase, 2018). In many ecological communities species, sorting has been recognized as the prevalent structuring force (Cottenie, 2005; Soininen et al., 2011; Soininen, 2014). However, a lack of species sorting may occur in case of weak species specialization, as found for bdelloid rotifers (Fontaneto et al. 2011). Similarly, a very wide ecological tolerance of species leads to very poor environmental responses in nematodes compared to other benthic invertebrate taxa (de Mendoza et al., 2017). In direct gradient analyses and variation partitioning, this would emerge as a relatively low proportion of variation explained by environmental variables (Fig. 3, 'specialization'). Studies on meiofauna metacommunities that included different spatial scales found that the relevance of species sorting was scale-dependent, becoming less significant on larger scales, where dispersal-based processes seemed to dominate (Matsuda et al. 2015, Dümmer et al., 2016), which is in accordance with general expectations (Leibold \& Chase, 2018).

Despite the undeniable importance on species sorting due to biotic interactions (Cadotte et al., 2006), no information has been found on its possible effect in meiofaunal metacommunities. However, the paucity of studies addressing the role of biotic interactions within a metacommunity context is a general problem in ecology research (Soininen, 2014).

\section{Dispersal-based processes}

Treating spatial structure in meiofaunal metacommunities

The dispersal of individuals among local communities is the most significant regional process influencing metacommunity structure. In correlative field studies, the role of dispersal-based processes is best considered by examining the spatial structure of metacommunities. In our review, 16 studies analyzed the effect of space on meiofauna, using different ways: (i) by comparing metacommunity patterns between several spatial scales (Fontaneto et al., 2005; Matsuda et al., 2015; Dümmer et al., 2016), (ii) by testing the influence of geographical distances (Fontaneto \& Ricci, 2006) and the non-/linear effects of latitude and longitude (Fontaneto et al., 2011), and (iii) by testing the effect of nonlinear spatial variables modeled according to the geographical distances between sites (Escrivà et al., 2015; Zhai et al., 2015b; Michelson et al., 2016; Castillo-Escrivà et al., 2016a, b, 2017a, b; Rosati et al., 2017; de Campos et al., 2018). Most of the studies reported dispersal limitations (Escrivà et al., 2015; Zhai et al., 2015b; Castillo-Escrivà et al., 2016b, 2017a; Rosati et al. 2017; de Campos et al., 2018), fewer dispersal sufficiency (Fontaneto \& Ricci, 2006; Fontaneto et al., 2011; Matsuda et al., 2015; Michelson et al., 2016; de Campos et al., 2018), and in one a significant spatial structure was attributed to a dispersal surplus (Castillo-Escrivà et al., 2016a). The different results may reflect actual differences in the realized dispersal of the studied taxa within the particular metacommunities, i.e., the metacommunity context (Fig. 3). For example, the degree of habitat connectivity may be given by different landscape topography including dispersal barriers. However, the recorded spatial effects might have also been influenced by study design (Fig. 3) and used statistical methods (see below).

\section{Dispersal of ostracods}

The meiofaunal studies that aimed at quantifying the effect of space relatively to that of environment dealt all with ostracods. They found significant pure effects of space (0.4-27.9\% of explained variance), which was in five of twelve metacommunities even higher 
than the pure environmental effect (Fig. 2). The studies mostly came from discrete habitats (springs and lakes; Fig. 2 above dotted line) and concluded that, despite the adaptations that enable ostracods to successfully disperse over long distances, such as small propagules (Malmqvist et al., 1997), draughtresistant eggs (Martens et al., 2008), and parthenogenetic reproduction (Martens, 1998), the dispersal was probably infrequent, subject to random events, and thus limited within a given area (Zhai et al., 2015b). That is in line with Bohonak and Jenkins (2003), who argued that the high dispersal capacity of freshwater invertebrates does not necessarily indicate high rates of overland dispersal.

In contrast, the studies from connected habitats (headwater streams and floodplain; Fig. 2 below dotted line) were very rare. Nevertheless, in accordance with theoretical expectations (Fig. 3, 'connectedness'), the relative effect of space in these studies was low and not significant (de Campos et al., 2018) or attributed mostly to dispersal surplus (Castillo-Escrivà et al., 2016a). In variation partitioning, dispersal surplus may be detectable if the shared effect of environment and space is high but the correlation between environment and space is low (Cottenie, 2005). However, most usually assigning a significant spatial pattern either to dispersal limitations or surplus remains a matter of biological interpretation. Generally, a higher connectivity among sites increases the dispersal rate, especially in the highly connected patches of stream networks. In mid and downstream sections, watercourse dispersal may reach high rates, very probably increasing the effect of spatial structure via mass effects (Brown \& Swan, 2010). However, mass effects cannot be unequivocally concluded solely based on surplus dispersal, because also the other assumption of mass effects, i.e., the persistence of species despite their negative growth rates, would need to be met (Leibold \& Chase, 2018). Accordingly, Castillo-Escrivà et al. (2016a), who covered the whole stream network, suggested, first, that watercourse is the more important dispersal pathway than passive overland transport, and, second, that the mass effects involve swimming species of ostracods in wider streams, as these organisms are more likely to be transferred to suboptimal conditions compared to crawling species in headwaters. However, they also suggested that limited dispersal among isolated headwater sites might have also contributed to the significant spatial pattern (Castillo-Escrivà et al., 2016a).

\section{Dispersal of other meiofauna}

There has been a very little support for dispersal limitations in other meiofaunal groups than ostracods. No dispersal limitations were recorded for rotifers in mosses and lichens either at high altitudes (above $3000 \mathrm{~m}$ a.s.l., Fontaneto \& Ricci, 2006) or on a large regional scale $(1000 \mathrm{~km}$, Fontaneto et al., 2011). For nematodes in European lakes, dispersal limitations were suggested, based on the degree of turnover, only at supra-regional scale $(500-1000 \mathrm{~km})$ but not on smaller scales (Dümmer et al., 2016). At regional scale, nematodes were found capable of rapidly colonizing newly created habitats (Ptatscheck et al., 2015).

The lack of dispersal limitations in rotifers and nematodes, compared to ostracods, seem to correspond to the generally smaller size and thus lighter propagules of the former two groups (Fenchel \& Finlay, 2004; De Bie et al., 2012). Moreover, in addition to parthenogenesis, both rotifers and nematodes exhibit anhydrobiosis, which make them especially well adopted to dispersal by wind (Fontaneto, 2019). This was directly confirmed by the presence of rotifers and nematodes in aeroplankton (Ptatscheck et al., 2018), while no ostracods were found in that study. Due to their good dispersal ability and presumed ubiquity, nematodes may track the main aerial and aquatic pathways given a landscape topography. That is why they have been suggested as spatial null models, suitable for testing patterns in the assemblages of other, more environmentally dependent groups of organisms (de Mendoza et al., 2017). However, despite the potentially high dispersal rates of rotifers and nematodes, none of the reviewed studies convincingly suggested a dispersal surplus for them.

Evidence on the dispersal limitations of some meiofaunal taxa comes from studies on the smallest spatial scales (centimeters and tens of centimeters), at which the active dispersal of meiofauna becomes relevant (Fontaneto et al., 2005). For example, taxonspecific differences in active dispersal or body size can lead to nested patterns among the individual pools within a river reach (rotifers; Fontaneto et al., 2005) 
and along a vertical profile of bed sediments in streams (higher meiofaunal taxa; Omesová et al., 2008; Dražina et al., 2017). Sediment grain size and depth may be seen as a measure of habitat connectivity within the interstitial zone (Omesová et al., 2008).

The effects of metacommunity context and study design

The expected effects of different aspects of metacommunity context and study design can be best demonstrated for the most frequent study type, variation partitioning (Fig. 3). The main aspects of the metacommunity context (in addition to the habitat connectedness discussed above) are the spatial extent and environmental heterogeneity, which have opposing effects but are often mutually connected (Leibold \& Chase, 2018). On one hand, dispersal rates decrease as distances between sites increase, leading to a stronger spatial structure as the spatial extent increases (Soininen, 2014) (Fig. 3, 'spatial extent'). On the other hand, a larger spatial extent often captures more environmental heterogeneity (Wiens, 1989), which could enhance also the effect of species sorting (Mykrä et al., 2007) (Fig. 3, 'heterogeneity'). Further, the relative effect of space largely depends on how comprehensively the environment is introduced into a metacommunity analysis (Fig. 3, 'number of environmental variables'). The degree of environmental filtering was shown to strongly positively correlate with the number of included environmental variables (Soininen, 2014). A significant spatial structure can thus often be an artifact of unmeasured, spatially structured environmental variability (Cottenie, 2005; Castillo-Escrivà et al., 2017a).

Unfortunately, we could not verify the effects of the spatial extent (50-497 km) or number of environmental variables (8-21) within the variation partitioning studies due to their low number and large differences in study design (Fig. 2, Online Resource 2). Neither could we assess the role of environmental heterogeneity, because of the lack of objective measurement. We can only suggest that the single reported absence of a spatial structure in an ostracod metacommunity, determined in 10 lakes over a steep environmental gradient (Castillo-Escrivà et al., 2017b), might be the consequence of a very high environmental heterogeneity.
The fraction of unexplained variation in the meiofauna studies was mostly larger (40.9-93.8\%) (Fig. 2) than the usual $50 \%$ reported by Leibold and Chase (2018). We suggest that the residuals may be positively linked with an increasing number of sites and species (Fig. 3, 'number of species and sites') (Online Resource 3). For example, the relatively large proportion of explained variation in Castillo-Escrivà et al. (2016b, 2017a) may be due to the relatively low number of sites and species (Table 2). This would be in line with the general expectation that a larger sample size encompass more environmental and spatial heterogeneity and a larger species pool with a wider range of ecological responses (Mykrä et al., 2007).

Further, the amount of explained variation may be affected by the data type (Table 2), because species presence/absence and abundance may be driven by different processes (Fig. 3, 'data type'). Generally, species abundances had stronger response to environmental gradients than the presence/absence data which are in turn sensitive to rare species (Heino et al., 2010; Soininen, 2014). Consequently, more variation can be explained in abundance than in the presence/absence data (e.g., Cushman \& McGarigal, 2004; Beisner et al., 2006; Heino et al., 2010). Higher environmental effects and larger residuals for abundance data were observed in the variation partitioning studies, although they could not be confirmed statistically (Online Resource 4).

Effect of statistical methods

The resulted role of spatial structure in individual studies may be further influenced by methodological biases. In our review, this especially concerns the use of variation partitioning versus Mantel test. Most evidence on dispersal limitations was obtained from studies using variation partitioning between environmental and eigenvector spatial variables. However, variation partitioning applied in combination with the advanced spatial analysis may overestimate the role of dispersal because spatial variables are analyzed using nonlinear pattern-detection (MEMs, PCNMs, AEMs), whereas for environmental variables only linear relationships are tested (e.g., RDA). Consequently, nonlinear environmental patterns may be falsely captured by the spatial components in variation partitioning (Leibold \& Chase, 2018). In contrast, all 
studies, which tested the relationships between species composition, environment, and space based on the correlations of distance matrices (Mantel test), found no significant spatial structure in the metacommunities regardless the studied spatial scale and taxonomic group, i.e., ostracods in ponds and lakes $(30 \mathrm{~km}$, Michelson et al., 2016) and rotifers in lichens (420 km, Fontaneto \& Ricci, 2006; ca 1000 km, Fontaneto et al., 2011).

However, the major advantage of variation partitioning is that, unlike Mantel test, it controls for spatial structure in environmental variables, by separating the pure and shared effects of environment and space (see shared and pure effects in Fig. 2). The intercorrelation of environment and space is very common in nature and it complicates distinguishing the influence of species sorting from that of dispersal. The overlap between environment and space may be minimized by appropriate study design (e.g., Grönroos et al., 2013) but it can be rarely completely avoided (Zhai et al., 2015a). Thus, to reliably assess the role of dispersal limitations in a metacommunity, it is preferable to use a combination of several statistical methods.

Comparison of meiofauna with other organisms

Our review suggests that evidenced by the determined dispersal limitations, ostracods, nematodes, and rotifers may differ in their dispersal ability in ascending order. These differences probably reflect body size of the respective groups and better dispersal of nematodes and rotifers by wind vs. the need of ostracods for animal vectors. This is, first, in accordance with the key effect of body size and dispersal mode on dispersal abilities of taxa in general (De Bie et al. 2012) and, second, an indication that meiofauna is a heterogeneous group regarding dispersal capacity.

The latter complicates a reconsideration of the degree of spatial structuring proposed for meiobenthic metacommunities compared to other aquatic organismal groups (Fig. 1). Spatial structuring is very probably stronger for fish and macrophytes (Beisner et al., 2006; Padial et al., 2014) than for meiofauna. On the contrary, the extremely mobile groups with very small body size such as protists, bacteria and phytoplankton are usually not subjected to dispersal limitations at all (Beisner et al., 2006; Fontaneto et al., 2006). However, unlike ostracods, the rotifers may show equally unlimited dispersal as the unicellular organisms, at least in semiterrestrial habitats (Fontaneto et al., 2011).

The dispersal ability of meiofauna likely highly overlaps with that of macroinvertebrates and zooplankton (Fig. 1). For macroinvertebrates, dispersal mode becomes probably more important than body size: active dispersers, although usually bigger in size, seem to track environmental conditions better than passive dispersers on regional scales (Grönroos et al., 2013). And, passive macroinvertebrate dispersers showed significant spatial structure due to limited dispersal among isolated sites (Rádková et al. 2014). Where exactly meiofauna should stand in comparison to passive and active macroinvertebrate dispersers remains unclear. Zooplankton metacommunities seem to be more affected by spatial constraints than bacteria and phytoplankton (Beisner et al., 2006). However, in a study on metacommunities of a floodplain system, the spatial effect was not significant for zooplankton at all (Padial et al., 2014). We assumed that the association of meiofauna with substrate might lead to more limited overland and watercourse dispersal than in the pelagic zooplankton, which has otherwise both similar size and dispersal mode as meiofauna. However, we could not confirm nor contradict this assumption based on our review.

The lack of report of mass effects in meiofauna is in apparent contrast with the finding of Cottenie (2005), who recognized mass effects in combination with species sorting as the second most relevant metacommunity paradigm in general (metacommunities of zooplankton and terrestrial plants). It might have been an indirect evidence for the effect of association with substrate in meiofauna dispersal. However, sediment dwelling meiofauna may drift in high numbers (Clifford, 1972; Palmer, 1992), and the paucity of evidence for mass effects in meiofauna may be simply due to the lack of relevant research in lotic habitats.

\section{Local stochasticity}

The central aim of metacommunity ecology is to assess the relative importance of stochastic processes in metacommunities (Vellend et al., 2014). At local scale, stochastic processes include compositional changes of a community, whether due to birth, death, immigration or emigration, that occur at random with respect to species identity (Vellend et al., 2014). These processes, termed colonization-extinction dynamics, 
or stochastic demography are an underlying assumption of neutral theory and patch dynamics (see Table 1). Among the reviewed meiofaunal metacommunity studies, only Tomasových and Kidwell (2010) directly included predictions based on colonizationextinction dynamics (in addition to those of neutral theory and mass effects) into their model of temporal turnover in fossil ostracod metacommunities. However, they were unable to distinguish local-scale processes due to strong time averaging (Tomasových \& Kidwell, 2010). Although the other studies did not explicitly investigate local stochastic processes, some of them consider their occurrence within meiofaunal metacommunities (e.g., Fontaneto et al., 2011; Rosati et al., 2017; de Campos et al., 2018).

Demographic stochasticity may become apparent at the absence of deterministic processes due to low specialization of species, as suggested for bdelloid rotifers (Fontaneto et al., 2011), and when dispersal is fast but random, as found for nematodes in artificial dendrotelmata (Ptatscheck et al., 2015). Further, demographic stochasticity seems to be more important in small habitats, characterized also by lower heterogeneity and greater isolation, because their populations are more prone to stochastic extinctions and colonization (MacArthur \& Wilson, 1967; Fukami, 2011). However, for meiofaunal metacommunities in the small habitats such as dendrotelmata (Ptatscheck et al., 2015) and patches of moss and lichens (Fontaneto et al., 2005), colonization-extinctions might be confounded by priority effects, which generally occur when the first colonists gain numerical advantage over subsequent competitors, thereby preventing further immigrations (De Meester et al., 2016). Priority effects, however, might have also influenced ostracod metacommunities in lakes, as suggested by a comparison of living and fossil assemblages (Castillo-Escrivà et al., 2017a).

In variation partitioning, stochastic demography can be included in residuals, together with the nonrandom variation due to unmeasured latent variables, correlations among species, and the interactions between space and environment (Leibold \& Chase, 2018). Accordingly, the large proportion of unexplained variation in the ostracod metacommunity of springs, threatened by desiccation due to dry climate, was attributed to a higher probability of extinctions and colonization (Rosati et al., 2017). However, generally species in springs and headwaters may be capable of demographic adaptations that result in lower extinction rates and therefore enable their larger persistence (Brown \& Swan, 2010). This may reduce the importance of colonization-extinction processes in metacommunities of these isolated habitats.

Conclusions and future research perspectives

The metacommunity framework allows simultaneous considerations of multiple processes on multiple scales (Leibold \& Chase, 2018). However, our review shows that (i) despite its wide acceptance within contemporary ecological research, meiobenthologists do not use this concept very often. With respect to our initially formulated aims, we have shown that (ii) niche-based processes were the prevalent structuring mechanisms in meiofauna. The role of (iii) dispersalbased processes seemed to be largely dependent on the metacommunity context and study design but these effects could not be sufficiently disentangled due to an insufficient number of studies eligible for review. Nevertheless, our results suggest that ostracods are more limited by dispersal than either nematodes or rotifers, and there is very little evidence of a dispersal surplus. Indications for (iv) local stochastic processes were found in several studies and may be very relevant for meiofaunal species with low degree of specialization (e.g., bdelloid rotifers) and metacommunities in small habitats (e.g., dendrotelmata).

The final aim of this review was to encourage further metacommunity research in meiofauna. Assessing the actual role of dispersal in metacommunities remains generally challenging (Jacobson \& Peres-Neto, 2010). Most relevant interpretations of spatial structure detected in metacommunities are those supported by assessment of dispersal rates with respect to a habitat type and scale. Here, studies allowing comparisons of different taxa sampled from the same sites would be very informative, especially if metacommunity subsets defined according to species traits are analyzed separately (Hájek et al., 2011; Rádková et al., 2014). Our results suggest that differences in the size and dispersal modes among individual meiofaunal groups may lead to different metacommunity structuring. Thus, different spatial effects might be expected also among other meiofaunal taxa, e.g., tardigrades, mites, and harpacticoids. Moreover, in addition to body size, dispersal mode, and the presence of resting stages, other species traits 
such as population size and fecundity may have a significant role for the dispersal efficiency in meiofauna (Rundle et al., 2007).

Further, to better quantify dispersal, studies covering several spatial scales and different parts of aquatic network are needed (Heino et al., 2015a). Investigations of colonization may be further supported by examining the genetic diversity of metapopulations (Haileselasie et al., 2016; Copilaş-Ciocianu \& Petrusek, 2017) and by DNA metabarcoding of whole assemblages.

A serious general objection to metacommunity research is that it is usually based on snapshot data and ignores temporal dynamics (Heino et al., 2015a). Incorporating long-term dimensions would enable the detection of long-term changes at ecological (Altermatt et al., 2008) and evolutionary (De Meester et al., 2016) scales.

The nearly complete lack of experimental studies on meiofauna (Hortal, 2011) is in contrast to those many on other aquatic organisms (e.g., Kneitel \& Miller, 2003; Cadotte \& Fukami, 2005). Clear hypothesis-driven experiments could highly improve our understanding of meiofaunal metacommunity processes. As for disentangling the role of biotic interactions, they could be included into the tests of meiofaunal metacommunity structure, either as biotic variables in observational studies (Gray et al., 2012; Göthe et al., 2013) or as elements in the experimental design (Kneitel \& Miller, 2003; Cadotte et al., 2006).

Apart from the insights into spatial ecology, the metacommunity concept may provide a useful framework for studying trophic interactions (Massol et al., 2011) and the influence of individual metacommunity processes on food web structures (e.g., Baiser et al., 2013). Such research might contribute to an integration of meiofauna into models of aquatic food webs.

Acknowledgements Open Access funding provided by Projekt DEAL. We are grateful to the German Federal Institute of Hydrology (BfG) for its support of this research. We also thank the two anonymous reviewers for their help to improve our manuscript.

\section{Compliance with ethical standards}

Conflict of interest The authors have no conflicts of interest to declare.

Open Access This article is licensed under a Creative Commons Attribution 4.0 International License, which permits use, sharing, adaptation, distribution and reproduction in any medium or format, as long as you give appropriate credit to the original author(s) and the source, provide a link to the Creative
Commons licence, and indicate if changes were made. The images or other third party material in this article are included in the article's Creative Commons licence, unless indicated otherwise in a credit line to the material. If material is not included in the article's Creative Commons licence and your intended use is not permitted by statutory regulation or exceeds the permitted use, you will need to obtain permission directly from the copyright holder. To view a copy of this licence, visit http://creativecommons.org/licenses/by/4.0/.

\section{References}

Altermatt, F., V. I. Pajunen \& D. Ebert, 2008. Climate change affects colonization dynamics in a metacommunity of three Daphnia species. Global Change Biology 14: 1209-1220.

Baiser, B., H. L. Buckley, N. J. Gotelli \& A. M. Ellison, 2013. Predicting food-web structure with metacommunity models. Oikos 122: 492-506.

Beisner, B. E., P. R. Peres-Neto, E. S. Lindström, A. Barnett \& M. L. Longhi, 2006. The role of environmental and spatial processes in structuring lake communities from bacteria to fish. Ecology 87: 2985-2991.

Bohonak, A. J. \& D. G. Jenkins, 2003. Ecological and evolutionary significance of dispersal by freshwater invertebrates. Ecology Letters 6: 783-796.

Borcard, D., P. Legendre \& P. Drapeau, 1992. Partialling out the spatial component of ecological variation. Ecology 73 : 1045-1055.

Brown, B. L. \& C. M. Swan, 2010. Dendritic network structure constrains metacommunity properties in riverine ecosystems. The Journal of Animal Ecology 79: 571-580.

Cadotte, M. W. \& T. Fukami, 2005. Dispersal, spatial scale, and species diversity in a hierarchically structured experimental landscape. Ecology Letters 8: 548-557.

Cadotte, M. W., A. M. Fortner \& T. Fukami, 2006. The effects of resource enrichment, dispersal, and predation on local and metacommunity structure. Oecologia 149: 150-157.

Castillo-Escrivà, A., J. Rueda, L. Zamora, R. Hernández, M. D. Moral \& F. Mesquita-Joanes, 2016a. The role of watercourse versus overland dispersal and niche effects on ostracod distribution in Mediterranean streams (eastern Iberian Peninsula). Acta Oecologica 73: 1-9.

Castillo-Escrivà, A., L. Valls, C. Rochera, A. Camacho \& F. Mesquita-Joanes, 2016b. Spatial and environmental analysis of an ostracod metacommunity from endorheic lakes. Aquatic Sciences 78: 707-716.

Castillo-Escrivà, A., L. Valls, C. Rochera, A. Camacho \& F. Mesquita-Joanes, 2017a. Disentangling environmental, spatial, and historical effects on ostracod communities in shallow lakes. Hydrobiologia 787: 61-72.

Castillo-Escrivà, A., L. Valls, C. Rochera, A. Camacho \& F. Mesquita-Joanes, 2017b. Metacommunity dynamics of Ostracoda in temporary lakes: overall strong niche effects except at the onset of the flooding period. Limnologica 62: 104-110.

Chase, J. M., 2007. Drought mediates the importance of stochastic community assembly. Proceedings of the National Academy of Sciences 104: 17430-17434. 
Clifford, H. F., 1972. Drift of invertebrates in an intermittent stream draining marshy terrain of west-central Alberta. Canadian Journal of Zoology 50: 985-991.

Copilaş-Ciocianu, D. \& A. Petrusek, 2017. Phylogeography of a freshwater crustacean species complex reflects a long-gone archipelago. Journal of Biogeography 44: 421-432.

Cottenie, K., 2005. Integrating environmental and spatial processes in ecological community dynamics. Ecology Letters 8: 1175-1182.

Cushman, A. S. \& K. McGarigal, 2004. Patterns in the speciesenvironment relationship depend on both scale and choice of response variables. Oikos 105: 117-124.

De Bie, T., L. De Meester, L. Brendonck, K. Martens, B. Goddeeris, D. Ercken, H. Hampel, L. Denys, L. Vanhecke, K. Van der Gucht, J. van Wichelen, W. Vyverman \& S. A. J. Declerck, 2012. Body size and dispersal mode as key traits determining metacommunity structure of aquatic organisms. Ecology Letters 15: 740-747.

de Campos, R., F. M. Lansac-Tôha, E. D. O. da Conceição, K. Martens \& J. Higuti, 2018. Factors affecting the metacommunity structure of periphytic ostracods (Crustacea, Ostracoda): a deconstruction approach based on biological traits. Aquatic Sciences 80: 381 .

Dražina, T., M. Špoljar, B. Primc \& I. Habdija, 2017. Distribution of rotifers and other meiofauna in the bryophytes and hyporheic zone of a karst hydrosystem - an example of a nested community. Marine and Freshwater Research 68: 43-52.

De Meester, L., J. Vanoverbeke, L. J. Kilsdonk \& M. C. Urban, 2016. Evolving perspectives on monopolization and priority effects. Trends in Ecology \& Evolution 31: 136-146.

de Mendoza, G., W. Traunspurger, A. Palomo \& J. Catalan, 2017. Nematode distributions as spatial null models for macroinvertebrate species richness across environmental gradients: a case from mountain lakes. Ecology and Evolution 7: 3016-3028.

Declerck, S. A. J., J. S. Coronel, P. Legendre \& L. Brendonck, 2011. Scale dependency of processes structuring metacommunities of cladocerans in temporary pools of HighAndes wetlands. Ecography 34: 296-305.

Dümmer, B., K. Ristau \& W. Traunspurger, 2016. Varying patterns on varying scales: a metacommunity analysis of nematodes in European lakes. PLoS ONE 11: e0151866.

Escrivà, A., J. Poquet \& F. Mesquita-Joanes, 2015. Effects of environmental and spatial variables on lotic ostracod metacommunity structure in the Iberian Peninsula. Inland Waters 5: 283-294.

Fenchel, T. \& B. J. Finlay, 2004. The ubiquity of small species: patterns of local and global diversity. BioScience 54: 777-784.

Fenchel, T. M., 1978. The ecology of micro-and meiobenthos. Annual Review of Ecology and Systematics 9: 99-121.

Fontaneto, D., 2019. Long-distance passive dispersal in microscopic aquatic animals. Movement ecology 7: 10.

Fontaneto, D. \& C. Ricci, 2006. Spatial gradients in species diversity of microscopic animals: the case of bdelloid rotifers at high altitude. Journal of Biogeography 33: 1305-1313.

Fontaneto, D., M. Westberg \& J. Hortal, 2011. Evidence of weak habitat specialisation in microscopic animals. PLoS ONE 6: e23969.
Fontaneto, D., G. Melone \& C. Ricci, 2005. Connectivity and nestedness of the meta-community structure of moss dwelling bdelloid rotifers along a stream. Hydrobiologia 542: 131-136.

Fontaneto, D., G. F. Ficetola, R. Ambrosini \& C. Ricci, 2006. Patterns of diversity in microscopic animals: are they comparable to those in protists or in larger animals? Global Ecology and Biogeography 15: 153-162.

Fukami, T., 2011. Community assembly dynamics in space. In Verhoef, H. A. \& P. J. Morin (eds), Community Ecology: Processes, Models, and Applications. Oxford University Press, Oxford: 45-54.

García-Roger, E. M., E. Lubzens, D. Fontaneto \& M. Serra, 2019. Facing adversity: dormant embryos in rotifers. Biological Bulletin 237: 119-144.

Gause, G. F., 1936. The principles of biocoenology. The Quarterly Review of Biology 11: 320-336.

Giere, O., 2009. Meiobenthology: The Microscopic Motile Fauna of Aquatic Sediments, 2nd edn. Springer, Heidelberg.

Göthe, E., D. G. Angeler, S. Gottschalk, S. Löfgren \& L. Sandin, 2013. The influence of environmental, biotic and spatial factors on diatom metacommunity structure in Swedish headwater streams. PLoS ONE 8: e72237.

Göthe, E., A. Baattrup-Pedersen, P. Wiberg-Larsen, D. Graeber, E. A. Kristensen \& N. Friberg, 2017. Environmental and spatial controls of taxonomic versus trait composition of stream biota. Freshwater Biology 62: 397-413.

Gravel, D., C. D. Canham, M. Beaudet \& C. Messier, 2006. Reconciling niche and neutrality: the continuum hypothesis. Ecology Letters 9: 399-409.

Gray, D. K., S. E. Arnott, J. A. Shead \& A. M. Derry, 2012. The recovery of acid-damaged zooplankton communities in Canadian Lakes: the relative importance of abiotic, biotic and spatial variables. Freshwater Biology 57: 741-758.

Grönroos, M., J. Heino, T. Siqueira, V. L. Landeiro, J. Kotanen \& L. M. Bini, 2013. Metacommunity structuring in stream networks: roles of dispersal mode, distance type, and regional environmental context. Ecology and Evolution 3: 4473-4487.

Haileselasie, T. H., J. Mergeay, L. J. Weider, R. Sommaruga, T. A. Davidson, M. Meerhoff, H. Arndt, K. Jürgens, E. Jeppesen \& L. De Meester, 2016. Environment not dispersal limitation drives clonal composition of Arctic Daphnia in a recently deglaciated area. Molecular Ecology 25: 5830-5842.

Hájek, M., J. Roleček, K. Cottenie, K. Kintrová, M. Horsák, A. Poulíčková, P. Hájková, M. Fránková \& D. Dítě, 2011. Environmental and spatial controls of biotic assemblages in a discrete semi-terrestrial habitat: comparison of organisms with different dispersal abilities sampled in the same plots. Journal of Biogeography 38: 1683-1693.

Havel, J. E. \& J. B. Shurin, 2004. Mechanisms, effects, and scales of dispersal in freshwater zooplankton. Limnology and Oceanography Letters 49: 1229-1238.

Heino, J., L. M. Bini, S. M. Karjalainen, H. MykrÃ, J. Soininen, L. C. G. Vieira \& J. A. F. Diniz-Filho, 2010. Geographical patterns of micro-organismal community structure: are diatoms ubiquitously distributed across boreal streams? Oikos 119: 129-137. 
Heino, J., A. S. Melo, T. Siqueira, J. Soininen, S. Valanko \& L. M. Bini, 2015a. Metacommunity organisation, spatial extent and dispersal in aquatic systems: patterns, processes and prospects. Freshwater Biology 60: 845-869.

Heino, J., T. Nokela, J. Soininen, M. Tolkkinen, L. Virtanen \& R. Virtanen, 2015b. Elements of metacommunity structure and community-environment relationships in stream organisms. Freshwater Biology 60: 973-988.

Higgins, R. P. \& H. Thiel (eds), 1988. Introduction to the study of meiofauna. Smithsonian Institution Press, Washington, DC, London.

Holyoak, M., M. A. Leibold \& R. D. Holt (eds), 2005. Metacommunities: Spatial Dynamics and Ecological Communities. The University of Chicago Press, Chicago.

Hortal, J., 2011. Geographic variation in the diversity of microbial communities: research directions and prospects for experimental biogeography. In Fontaneto, D. (ed), Biogeography of Microscopic Organisms: Is Everything Small Everywhere?, Vol. 79., The Systematics Association Special Volume Series Cambridge University Press, Cambridge: 335-357.

Hubbell, S. P., 2001. The unified neutral theory of biodiversity and biogeography. In Jordan, W. R., M. E. Gilpin \& J. D. Aber (eds), Monographs in Population Biology, 32nd edn. Princeton University Press, Princeton.

Jacobson, B. \& P. R. Peres-Neto, 2010. Quantifying and disentangling dispersal in metacommunities: how close have we come? How far is there to go? Landscape Ecology 25: 495-507.

Jenkins, D. G. \& M. O. Underwood, 1998. Zooplankton may not disperse readily in wind, rain, or waterfowl. Hydrobiologia 387/388: 15-21.

Juračka, P. J., S. A. J. Declerck, D. Vondrák, L. Beran, M. Černý \& A. Petrusek, 2016. A naturally heterogeneous landscape can effectively slow down the dispersal of aquatic microcrustaceans. Oecologia 180: 785-796.

Kaczmarek, Ł., M. Roszkowska, D. Fontaneto, M. Jezierska, B. Pietrzak, R. Wieczorek, I. Poprawa, J. Z. Kosicki, A. Karachitos \& H. Kmita, 2019. Staying young and fit? Ontogenetic and phylogenetic consequences of animal anhydrobiosis. Journal of Zoology 309: 1-11.

Kneitel, J. M. \& T. E. Miller, 2003. Dispersal rates affect species composition in metacommunities of Sarracenia purpurea inquilines. The American Naturalist 162: 165-171.

Landeiro, V. L., W. E. Magnusson, A. S. Melo, H. M. V. Espírto-Santo \& L. M. Bini, 2011. Spatial eigenfunction analyses in stream networks: do watercourse and overland distances produce different results? Freshwater Biology 56: 1184-1192.

Legendre, P. \& L. Legendre, 2012. Numerical ecology. In Beck, M. B. (ed), Developments in Environmental Modelling, 3rd edn. Elsevier, Amsterdam.

Leibold, M. \& G. M. Mikkelson, 2002. Coherence, species turnover, and boundary clumping: elements of meta-community structure. Oikos 97: 237-250.

Leibold, M. A. \& J. M. Chase, 2018. Metacommunity Ecology, Vol. 59., Monographs in Population Biology Princeton University Press, Princeton.

Leibold, M. A., M. Holyoak, N. Mouquet, P. Amarasekare, J. M. Chase, M. F. Hoopes, R. D. Holt, J. B. Shurin, R. Law, D. Tilman, M. Loreau \& A. Gonzalez, 2004. The metacommunity concept: a framework for multi-scale community ecology. Ecology Letters 7: 601-613.

Levin, S. A., 1970. Community equilibria and stability, and an extension of the competitive exclusion principle. The American Naturalist 104: 413-423.

Logue, J. B., N. Mouquet, H. Peter \& H. Hillebrand, 2011. Empirical approaches to metacommunities: a review and comparison with theory. Trends in Ecology \& Evolution 26: 482-491.

MacArthur, R. H. \& E. O. Wilson, 1967. The Theory of Island Biogeography. Princeton University Press, Princeton.

Malmqvist, B., C. Meisch \& A. N. Nilsson, 1997. Distribution patterns of freshwater Ostracoda (Crustacea) in the Canary Islands with regards to habitat use and biogeography. Hydrobiologia 347: 159-170.

Martens, K. (ed), 1998. Sex and parthenogenesis: evolutionary ecology of reproductive modes in non-marine Ostracods. Backhuys, Leiden.

Martens, K., I. Schön, C. Meisch \& D. J. Horne, 2008. Global diversity of ostracods (Ostracoda, Crustacea) in freshwater. Hydrobiologia 595: 185-193.

Massol, F., D. Gravel, N. Mouquet, M. W. Cadotte, T. Fukami \& M. A. Leibold, 2011. Linking community and ecosystem dynamics through spatial ecology. Ecology Letters 14: 313-323.

Matsuda, J. T., K. Martens \& J. Higuti, 2015. Diversity of ostracod communities (Crustacea, Ostracoda) across hierarchical spatial levels in a tropical floodplain. Hydrobiologia 762: 113-126.

Mezquita, F., J. R. Roca \& G. Wansard, 1999. Moulting, survival and calcification: the effects of temperature and water chemistry on an ostracod crustacean (Herpetocypris intermedia) under experimental conditions. Archiv für Hydrobiologie 146: 219-238.

Michelson, A. V., L. E. Park Boush \& J. J. Pan, 2016. Discerning patterns of diversity from biogeographical distributions: testing models of metacommunity dynamics using nonmarine ostracodes from San Salvador Island, Bahamas. Hydrobiologia 766: 305-319.

Milesi, S. V., A. S. Melo \& Y. Chen, 2014. Conditional effects of aquatic insects of small tributaries on mainstream assemblages: position within drainage network matters. Canadian Journal of Fisheries and Aquatic Sciences 71: $1-9$.

Mykrä, H., J. Heino \& T. Muotka, 2007. Scale-related patterns in the spatial and environmental components of stream macroinvertebrate assemblage variation. Global Ecology and Biogeography 16: 149-159.

Olden, J. D., D. A. Jackson \& P. R. Peres-Neto, 2001. Spatial isolation and fish communities in drainage lakes. Oecologia 127: 572-585.

Omesová, M., M. Horsák \& J. Helesic, 2008. Nested patterns in hyporheic meta-communities: the role of body morphology and penetrability of sediment. Die Naturwissenschaften 95: 917-926.

Padial, A. A., F. Ceschin, S. A. J. Declerck, L. De Meester, C. C. Bonecker, F. A. Lansac-Tôha, L. Rodrigues, L. C. Rodrigues, S. Train, L. F. M. Velho \& L. M. Bini, 2014. Dispersal ability determines the role of environmental, spatial and temporal drivers of metacommunity structure. PLoS ONE 9: e111227. 
Palmer, M. A., 1992. Incorporating lotic meiofauna into our understanding of faunal transport processes. Limnology and Oceanography 37: 329-341.

Presley, S. J., C. L. Higgins \& M. R. Willig, 2010. A comprehensive framework for the evaluation of metacommunity structure. Oikos 119: 908-917.

Ptatscheck, C., B. Dümmer \& W. Traunspurger, 2015. Nematode colonisation of artificial water-filled tree holes. Nematology 17: 911-921.

Ptatscheck, C., B. Gansfort \& W. Traunspurger, 2018. The extent of wind-mediated dispersal of small metazoans, focusing nematodes. Scientific Reports 8: 6814.

Rádková, V., J. Bojková, V. Křoupalová, J. Schenková, V. Syrovátka \& M. Horsák, 2014. The role of dispersal mode and habitat specialisation in metacommunity structuring of aquatic macroinvertebrates in isolated spring fens. Freshwater Biology 59: 2256-2267.

Robertson, A. L. \& A. M. Milner, 2006. The influence of stream age and environmental variables in structuring meiofaunal assemblages in recently deglaciated streams. Limnology and Oceanography Letters 51: 1454-1465.

Robeson, M. S., A. J. King, K. R. Freeman, C. W. Birky, A. P. Martin \& S. K. Schmidt, 2011. Soil rotifer communities are extremely diverse globally but spatially autocorrelated locally. Proceedings of the National Academy of Sciences of the United States of America 108: 4406-4410.

Rocha, M. P., J. Heino, L. F. Machado-Velho, F. M. LansacTôha \& F. A. Lansac-Tôha, 2017. Fine spatial grain, large spatial extent and biogeography of macrophyte-associated cladoceran communities across Neotropical floodplains. Freshwater Biology 62: 559-569.

Rosati, M., G. Rossetti, M. Cantonati, V. Pieri, J. R. Roca \& F. Mesquita-Joanes, 2017. Are aquatic assemblages from small water bodies more stochastic in dryer climates? An analysis of Ostracod spring metacommunities. Hydrobiologia 793: 199-212.

Rundle, S. D., D. T. Bilton \& A. Foggo, 2007. By wind, wings or water: body size, dispersal and range size in aquatic invertebrates. In Hildrew, A. G., D. G. Raffaelli \& R. Edmonds-Brown (eds), Body Size: The Structure and Function of Aquatic Ecosystems., Ecological Reviews Cambridge University Press, Cambridge: 186-209.

Shurin, J. B., P. Amarasekare, J. M. Chase, R. D. Holt, M. F. Hoopes \& M. A. Leibold, 2004. Alternative stable states and regional community structure. Journal of Theoretical Biology 227: 359-368.

Shurin, J. B., K. Cottenie \& H. Hillebrand, 2009. Spatial autocorrelation and dispersal limitation in freshwater organisms. Oecologia 159: 151-159.

Siepielski, A. M. \& M. A. McPeek, 2010. On the evidence for species coexistence: a critique of the coexistence program. Ecology 91: 3153-3164.

Soininen, J., 2014. A quantitative analysis of species sorting across organisms and ecosystems. Ecology 95: 3284-3292.

Soininen, J., J. J. Korhonen, J. Karhu \& A. Vetterli, 2011. Disentangling the spatial patterns in community composition of prokaryotic and eukaryotic lake plankton. Limnology and Oceanography 56: 508-520.
Tilman, D., 1997. Community invasibility, recruitment limitation, and grassland biodiversity. Ecology 78: 81-92.

Tomasových, A. \& S. M. Kidwell, 2010. The effects of temporal resolution on species turnover and on testing metacommunity models. The American Naturalist 175: 587-606.

Tonkin, J. D., F. Altermatt, D. S. Finn, J. Heino, J. D. Olden, S. U. Pauls \& D. A. Lytle, 2018. The role of dispersal in river network metacommunities: patterns, processes, and pathways. Freshwater Biology 63: 141-163.

Vanschoenwinkel, B., S. Gielen, M. Seaman \& L. Brendonck, 2009. Wind mediated dispersal of freshwater invertebrates in a rock pool metacommunity: differences in dispersal capacities and modes. Hydrobiologia 635: 363-372.

Vanschoenwinkel, B., A. Waterkeyn, M. Jocqué, L. Boven, M. Seaman \& L. Brendonck, 2010. Species sorting in space and time - the impact of disturbance regime on community assembly in a temporary pool metacommunity. Journal of the North American Benthological Society 29: 1267-1278.

Vellend, M., D. S. Srivastava, K. M. Anderson, C. D. Brown, J. E. Jankowski, E. J. Kleynhans, N. J. B. Kraft, A. D. Letaw, A. A. M. Macdonald, J. E. Maclean, I. H. Myers-Smith, A. R. Norris \& X. Xue, 2014. Assessing the relative importance of neutral stochasticity in ecological communities. Oikos 123: 1420-1430.

Viana, D. S., J. Figuerola, K. Schwenk, M. Manca, A. Hobaek, M. Mjelde, C. D. Preston, R. J. Gornall, J. M. Croft, R. A. King, A. J. Green \& L. Santamaría, 2016. Assembly mechanisms determining high species turnover in aquatic communities over regional and continental scales. Ecography 39: 281-288.

Wellborn, G. A., D. K. Skelly \& E. E. Werner, 1996. Mechanisms creating community structure across a freshwater habitat gradient. Annual Review of Ecology and Systematics 27: 337-363.

Wiens, J. A., 1989. Spatial scaling in ecology. Functional Ecology 3: 385-397.

Wilson, C. G. \& P. W. Sherman, 2013. Spatial and temporal escape from fungal parasitism in natural communities of anciently asexual bdelloid rotifers. Proceedings of the Royal Society B 280: 20131255.

Wilson, D. S., 1992. Complex interactions in metacommunities, with implications for biodiversity and higher levels of selection. Ecology 73: 1984-2000.

Winegardner, A. K., B. K. Jones, I. S. Y. Ng, T. Siqueira \& K. Cottenie, 2012. The terminology of metacommunity ecology. Trends in Ecology \& Evolution 27: 253-254.

Zhai, M., D. Hřívová \& T. Peterka, 2015a. The harpacticoid assemblages (Copepoda: Harpacticoida) in the Western Carpathian spring fens in relation to environmental variables and habitat age. Limnologica 53: 84-94.

Zhai, M., O. Nováček, D. Výravský, V. Syrovátka, J. Bojková \& J. Helešic, 2015b. Environmental and spatial control of ostracod assemblages in the Western Carpathian spring fens. Hydrobiologia 745: 225-239.

Publisher's Note Springer Nature remains neutral with regard to jurisdictional claims in published maps and institutional affiliations. 